\title{
Research of Port Competitiveness Evaluation Based on Attribute Evaluation Method
}

\author{
Xueyan DUAN ${ }^{1}$, JieQiong LIU $^{2}$ \\ ${ }^{1,2}$ Department of Economic and Management ,Shanghai Polytechnic University, \\ 201209,Shanghai, China \\ ${ }^{1} x y d u a n @ s s p u . e d u . c n ; 2 j q l i u @ s s p u . e d u . c n$
}

\begin{abstract}
Attribute Evaluation Method can simulate the psychological preferences of decision makers and give the evaluation results in line with the psychology of decision makers. The effectiveness of this method is verified through the ranking of 11 ports' competitiveness, which also provides a new idea for port competitiveness evaluation.
\end{abstract}

Keywords: Port; Competitiveness; Evaluation; Attribute Evaluation Method; Preferences

\section{Introduction and Literature review}

Attribute Theory was put forward by Professor Jiali Feng. Attribute Coordinate Comprehensive Evaluation Method(ACCEM) is a comprehensive evaluation method based on Attribute Theory. ACCEM can simulate normal thinking pattern of people which can reflect the preferences or preference curve of evaluators and can be used in the empirical decision-making and uncertainty mathematical analysis. Some scholars applied ACCEM and obtained some results. ACCEM has already be used in College entrance examination evaluation system(Xie,2002), Enterprise's Productive Forces Evaluation(Xu,2002), 3PL's Core Competence Evaluation(Duan,2006), Software Enterprises' Competence(Xu,2006), Optimized Selection of Supplier in SCM (Li,2007), whose results turned out to be rather satisfactory. ACCEM are proved to be validity from these applications.

A port is the hub of a transportation system. Correct assessment of port competitiveness will directly affect the future development space of port. Some methods have been applied to port evaluation, such as AHP, FCE(Fuzzy Comprehensive Evaluation),DEA, TOPSIS. These studies mainly start from objective analysis and do not integrate into the psychological preferences of decision makers, which needs further study.

ACCEM provides a new idea for studying the evaluation of port competitiveness. It can not only objectively analyze the characteristics of port competitiveness, but also simulate the psychological preference curve of decision makers, which can provide a more reasonable evaluation result. 


\section{Attribute Coordinate Comprehensive Evaluation Method}

ACCEM establishes on the theory of Attribute Theory. Attribute theory method simulates people's normal thinking mode. Attribute theory reflects decision maker's psychological preference and psychological preference curve based on qualitative mapping theory.

In ACCEM, we assume that $X=\left\{x_{i}=\left(x_{i 1}, x_{i 2}, \cdots, x_{i m}\right) \mid x_{i j}\left(0 \leq x_{i j} \leq 100\right)\right\}$ is the set of all the solutions. $S_{T}=\left\{x_{i}=\left(x_{i 1}, x_{i 2}, \cdots, x_{i m}\right) \mid \sum_{j=1}^{m} x_{i j}=T\right\}$ is the set of all the solutions that the total score is equal to $T$. Their intersection $S_{T} \cap X$ forms a hyperplane of equal total $T\left(T_{0} \leq T \leq 100\right)$ or $m-1$ dimensional simplex. $\left\{x_{k}, k=1, \cdots, s\right\} \subseteq S_{T} \cap X$ is the set of sample scheme $x$ whose total score is equal to $T$.

Suppose decision maker $z$ picked $t$ schemes that he was fairly satisfied, $\left\{x^{h}, h=1, \cdots, t\right\}$, and he gave each scheme a score $v^{h}\left(x^{h}\right)$. Then the center of gravity can be get with $v^{h}\left(x^{h}\right)$ as the weight. We can use machine learning to get the locally satisfactory solution. When the training sample set $\left\{x_{k}\right\}$ is large enough, the training times are enough, and the scheme set $\left\{x^{h}(z)\right\}$ that decision maker $z$ picked is enough, the center of gravity $b\left(\left\{x^{h}(z)\right\}\right)$ will gradually approach the local optimal solution. Thus decision maker $z$ can use the local satisfaction function (1) to evaluate the satisfaction of all schemes $\left\{x_{i}=\left(x_{i 1}, x_{i 2}, \cdots, x_{i m}\right)\right\}$ in $S_{T} \cap X$.

$$
\operatorname{sat}\left(x_{i}, \mathrm{z}\right)=\exp \left(-\frac{\sum_{j=1}^{m} w_{j}\left|x_{i j}-b_{i j}\left(\left\{x^{h}(z)\right\}\right)\right|}{\sum_{j=1}^{m} w_{j}\left(b_{i j}\left(\left\{x^{h}(z)\right\}\right)-\delta_{j}\right)}\right)
$$

Considering the continuous change of decision make $z$ 's psychological standard, the set of locally satisfactory solutions $\left\{\left.b\left(\left\{x^{h}(z)\right\}\right)\right|_{T \in[100,100 \times n]}\right\}$ can be viewed as a line $L\left(b\left(\left\{x^{h}(z)\right\}\right)\right)$, which is called the local optimal line or mental standard line of decision maker $z$. The result of $L\left(b\left(\left\{x^{h}(z)\right\}\right)\right)$ can be calculated by interpolation.

Being proved mathematically and debugged many times, global consistency coefficient $\lambda(x, z)$ is introduced in order to get a global satisfaction solution from the local optimal line $L\left(b\left(\left\{x^{h}(z)\right\}\right)\right)$. 


$$
\lambda(x, z)=\left(\frac{\sum_{i=1}^{m} X_{i j}}{\sum_{j=1}^{m} X_{j}}\right)^{\sum_{j=1}^{m} x_{j}}
$$

Global satisfactory solution is:

$$
\operatorname{sat}(x, \mathrm{z})=\lambda(x, \mathrm{z}) * \operatorname{sat}\left(x_{i}, \mathrm{z}\right)=\left(\frac{\sum_{i=1}^{m} x_{i j}}{\sum_{j=1}^{m} X_{j}}\right)^{\frac{\sum_{j=1}^{m} x_{j}}{m} \sum_{i=1}^{m}} * \exp \left(-\frac{\sum_{j=1}^{m} w_{j}\left|x_{i j}-b_{i j}\left(\left\{x^{h}(z)\right\}\right)\right|}{\sum_{j=1}^{m} w_{j}\left(b_{i j}\left(\left\{x^{h}(z)\right\}\right)-\delta_{j}\right)}\right)(3)
$$

Using the formula (3), we can evaluate the global satisfaction of the objects in the whole decision space. The specific steps of ACCEM are as described below:

(1) Determine the feasible schemes that influence the decision making, analyze the attribute characteristics of each feasible scheme, and evaluate and quantify the properties of each feasible scheme

(2) Qualitative mapping function is used to normalize attribute utility value nonlinearly.

(3) $T_{0}$ is set as the critical total score. In $\left(T_{0}, 100 m\right)$. A number of points $\left(T_{1}, T_{2}, \cdots, T_{n-1}\right)$ are uniformly selected according to the requirements of curve fitting. At each point with a total score of $T_{i}=(i=1,2, \cdots, n-1)$, several sample schemes are selected for study to find the center of gravity coordinates with a total score of $T_{i}=(i=1,2, \cdots, n-1)$, which is locally satisfactory solution.

(4) Using the interpolation formula, the curve fitting was carried out to find the psychological standard line which is also called local most satisfactory solution line.

(5)According to (3), the global satisfaction of each scheme is calculated, and the ranking is conducted from large to small to obtain the most satisfactory solution.

\section{Attribute characteristics of Port Competitiveness}

Competitiveness is a strong comprehensive ability that participants of both or all parties expressed by comparing. Port competitive ability can be defined as port's competitive advantage in production capacity, value creation, sustainable development ,etc. So we choose Port Infrastructure, Port Scale and Port Greening as one class attribute. Each one class attribute has three secondary attributes. 
(1) Port Infrastructure: Port infrastructure refer to the necessary facilities for completing the most basic functions of port logistics. Generally including port channel, breakwater, anchorage, dock, berth, port traffic, etc.

(2) Port Scale: Port scale includes the following main contents: Parliamentary terminals, berths, warehouses and other facilities have reached the scale; Ownership and technical level of major equipment such as handling machinery; The number and quality of employees; Strive for economic benefits, etc.

(3) Port Greening: Green port refers to the development mode of environmental protection, ecology, low energy consumption and low emission. Energy consumption, pollutant discharge and damage to the ecological environment will be minimized to obtain the maximum socio-economic and ecological benefits.

\section{Port Competitiveness Index System}

We have drawn lessons from studies on port evaluation indicators at home and abroad, carried out theoretical analysis and expert consultation, and finally formed a port competitiveness evaluation system with three levels. Each Criterion layer indicator layer has three sub-indicators. Altogether there are 11 indicators in the third indicator layer. The structure of the whole index system is shown in the Table1.

Table 1. Port Competitiveness Evaluation Index System

\begin{tabular}{|c|c|c|}
\hline $\begin{array}{l}\text { Target } \\
\text { layer }\end{array}$ & Criterion layer & Indicator layer \\
\hline \multirow{9}{*}{$\begin{array}{c}\text { Port } \\
\text { Competi- } \\
\text { tiveness } \\
\text { (U) }\end{array}$} & \multirow{3}{*}{ Port Infrastructure(u1) } & Level channel proportion（u11） \\
\hline & & Berth quantity（u12） \\
\hline & & Shoreline length（u13） \\
\hline & \multirow{3}{*}{ Port scale (u2) } & Proportion of water transport freight turnover $(\mathbf{u} 21)$ \\
\hline & & port throughput（u22） \\
\hline & & GDP of port city（u23） \\
\hline & \multirow{3}{*}{ Port Greening(u3) } & Environmental protection investment index (u31) \\
\hline & & Energy Consumption per Unit of GDP（u32） \\
\hline & & Afforestation coverage in the port (u33) \\
\hline
\end{tabular}

\section{Empirical study}

We choose 11 ports to carry out empirical research. Index original values of 11 ports are standardized using Z-score method.

Then we process the data with formula as $x_{i j}^{\prime}=x_{i j} * 10+50$ so that the data is between 0 and 100. Datas afer standarizaion are shown in Table 2. 
Table 2. Datas afer Standarizaion of 11 Ports

\begin{tabular}{lccccccccc}
\hline & $\mathbf{u 1 1}$ & $\mathbf{u 1 2}$ & $\mathbf{u 1 3}$ & $\mathbf{U 2 1}$ & $\mathbf{U 2 2}$ & $\mathbf{u 2 3}$ & $\mathbf{U 3 1}$ & $\mathbf{U 3 2}$ & $\mathbf{U 3 3}$ \\
\hline port1 & 47.27 & 45.12 & 52.99 & 39.87 & 74.94 & 58.06 & 63.22 & 50.07 & 61.46 \\
\hline port2 & 33.17 & 46.91 & 46.78 & 60.94 & 53.61 & 50.63 & 59.93 & 55.08 & 37.22 \\
\hline port3 & 41.98 & 45.18 & 49.24 & 59.21 & 51.81 & 47.28 & 48.95 & 44.33 & 49.34 \\
\hline port4 & 59.62 & 56.95 & 52.77 & 57.77 & 48.83 & 43.12 & 48.01 & 56.52 & 46.92 \\
\hline port5 & 46.39 & 44.54 & 45.45 & 41.89 & 47.48 & 44.41 & 52.70 & 51.86 & 42.07 \\
\hline port6 & 62.26 & 47.34 & 42.04 & 57.19 & 46.89 & 44.45 & 51.77 & 34.29 & 59.03 \\
\hline port7 & 55.21 & 44.04 & 47.56 & 58.06 & 50.12 & 44.59 & 44.26 & 49.71 & 39.64 \\
\hline port8 & 50.80 & 44.63 & 41.52 & 51.99 & 45.41 & 56.91 & 29.52 & 53.29 & 44.49 \\
\hline port9 & 60.50 & 71.74 & 67.00 & 42.76 & 44.38 & 44.99 & 48.95 & 39.67 & 49.34 \\
\hline port10 & 42.87 & 44.21 & 39.86 & 40.16 & 42.54 & 43.74 & 46.14 & 67.99 & 59.03 \\
\hline port11 & 49.92 & 59.36 & 64.79 & 40.16 & 43.98 & 71.83 & 56.55 & 47.20 & 61.46 \\
\hline
\end{tabular}

Then we can evaluate 11 ports using ACCEM after indicators standardization . Because the index system is divided into three layers, we need to analyze layer by layer.

For example, One class index Port Infrastructure has three indicators. Take the three attributes as axes and three score $x\left(a_{j}\right)(j=1,2,3)$ of three attributes. Each port $x_{i}$ responses a $3 D$ coordinate points $x_{i j}=\left(x_{i 1}, x_{i 2}, x_{i 3}\right)$ in the $3 D$ decision-making coordinate. So we can establish 3 Lagrange interpolation equations as (4).

$$
\begin{aligned}
& G(T)=G\left(g_{1}(T), g_{2}(T), g_{3}(T),\right) \\
& \text { Amon them: } \begin{cases}g_{1}(T)=a_{01}+a_{11} T+a_{21} T^{2} & (4-1) \\
g_{2}(T)=a_{02}+a_{12} T+a_{22} T^{2} & (4-2) \\
g_{3}(T)=a_{03}+a_{13} T+a_{23} T^{2} & (4-3)\end{cases}
\end{aligned}
$$

Choose 3 total score which is $T_{\min }, T_{\max }$ and $T_{i}$ through the study of the sample we can get evaluation criteria points. Plug three evaluation criteria points in formula (5).

$$
g_{i}(T)=\frac{\left(T-x_{1}^{*}\right)\left(T-x_{2}^{*}\right)}{\left(x_{0}^{*}-x_{1}^{*}\right)\left(x_{0}^{*}-x_{2}^{*}\right)} a_{i 0}+\frac{\left(T-x_{0}^{*}\right)\left(T-x_{2}^{*}\right)}{\left(x_{1}^{*}-x_{0}^{*}\right)\left(x_{1}^{*}-x_{2}^{*}\right)} a_{i 1}+\frac{\left(T-x_{0}^{*}\right)\left(T-x_{1}^{*}\right)}{\left(x_{2}^{*}-x_{0}^{*}\right)\left(x_{2}^{*}-x_{1}^{*}\right)} a_{i 2}
$$

We can get nine coefficients of equation set. Plug nine coefficients in formula (4) to get the the interpolation curve $G(T)=G\left(g_{1}(T), g_{2}(T), g_{3}(T)\right.$, ) of evaluation standard curve $L\left(b\left(\left\{x^{h}(z)\right\}\right)\right)$. Then we can get any evaluation criteria in any total score plane. Using local satisfaction function and global satisfaction function, we can get the global satisfaction score of one class index Port Infrastructure.

In the same way we calculate global satisfaction of the other two indicators of one class index. 
Then take the three indexes of one class as three attributes to calculate global satisfaction score of target layer and sort. The whole calculation process can be realized through the computer software programming.

The final scores and ranking list are shown in Fig.1.

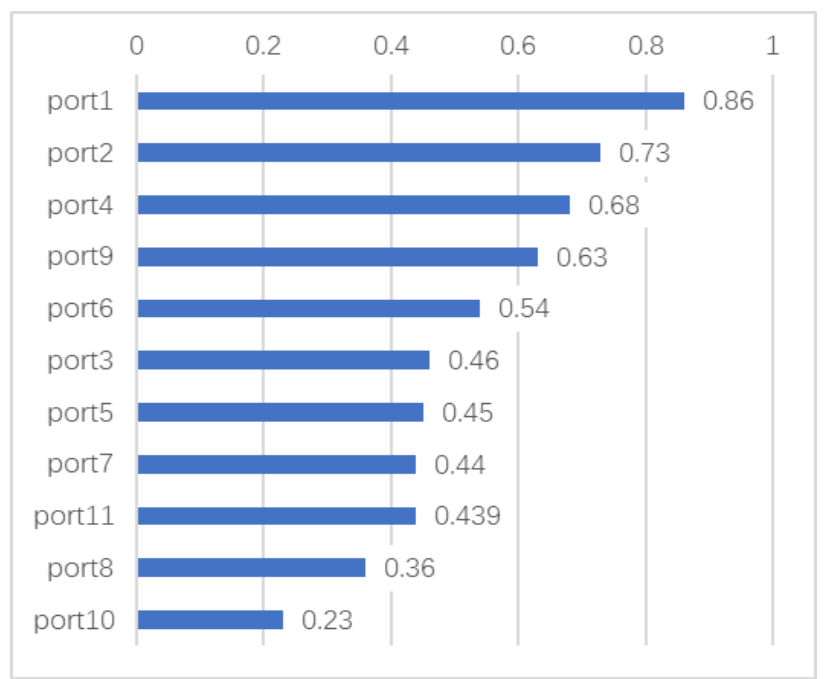

Figure 1. Final Evaluation Scores and Ranking of Port Competitiveness

\section{Conclusion}

In conclusion, ACCEM can simulate the psychological preference and change process of the evaluator. In addition, the port competitiveness can be evaluated and ranked according to the local psychological evaluation standard and the global psychological evaluation standard of the evaluator. From Figure1, we can see that the total score of port 3 and port5 is similar. By analyzing the original data, we can find that the throughput of port 3 is higher. This reflects that the psychological preference of the evaluator is more inclined to the throughput index. This shows that the evaluation principle of this method is in accordance with the preference of the evaluator. Different evaluators may have different evaluation results. This is the characteristic of ACCEM. ACCEM can give the evaluation results that meet the requirements of decision makers by constantly learning their psychological preferences. The research of this paper proves the validity of ACCEM, and broadens the thinking for the evaluation of port competitiveness, which plays the role of throwing bricks and introducing jade. 


\section{References}

1.FENG Jia-li,DONG Zhan-qiu.A mathematical model of sensation nuron detection based on attribute abstraction and integration[J].Computer Research and Development,1997, Vol.34(7):pp481-486

2.FENG Jia-li.The research on decision support system of nuclear accident emergency and it's computer realization[D].Beijing:Institute of Atomic Energy of China,2001.

3.FENG Jia-li.The qualitative mapping model of judgment and the classification of non-linear patterns[J].Journal of Guangxi Normal University:Natural Science Edition,2004, Vol.22(1):pp27-32.

4.FENG Jia-li.The recognition methods based on qualitative mapping model[J].Journal of Guangxi Normal University:Natural Science Edition,2004, Vol.22(2):pp14-18.

5.Qinpan WU,Jiali FENG, Zhanqiu DONG,Yongxing ZHANG: A Kind of Evaluation and Decision Model Based on Analysis and Learning of Attribute Coordinate,Journal of Nanjing University(Natural Sciences),39(2):182-188 (2003) (in Chinese)

6.Xiaolan XIE, Jianhua LIU, Qirong LU:Admissions decisions in the university entrance exam system,Journal of Guilin Engineering, 21(4):402-406(2001) (in Chinese)

7.Xueyan DUAN,Yongchang LIU,Guanglin XU,Evaluation on 3PL's core competence based on method of attribute theory,Journal of Shanghai Maritime University,27(1):41-43(2006) (in Chinese)

8.Guanglin XU,Yongchang LIU,Jiali FENG.Evaluation of Chinese Software Enterprises' Core Competence in Attribute Theory,Journal of Guangxi Normal University(Natural Science Edition), 2006, 24(4):34-37(2006)

9.Jianli LI, Yongchang LIU,Jiali FENG:Comprehensive Assessment \& Optimized Selection of Supplier in SCM Based on Attribute Theory, Logistics Technology,26(5):75-79. (2007)(in Chinese) 